\title{
Design and development of Robust Portable Trainers used in PLC and Pneumatic Laboratories
}

\section{Dr. Ali Alavizadeh, Purdue University Northwest}

Dr. Ali Alavizadeh is an Assistant Professor of Industrial Engineering Technology at Purdue University Northwest (Hammond, IN). Previously, he taught at Purdue University Fort Wayne (Fort Wayne, Indiana), The George Washington University (Washington, DC), and Morehead State University (Morehead, KY) in the areas of Industrial Engineering Technology, and Engineering Management and Systems Engineering. His industrial experiences include software engineering, systems engineering and analysis, and production optimization for private, governmental, and nongovernmental organizations. His research interests include numerical methods in solid and fluid mechanics, nonlinear dynamics, and complex systems modeling and simulation.

\section{Dr. Maged Mikhail, Purdue University Northwest}

Dr. Maged B.Mikhail, Assistant Professor, Mechatronics Engineering Technology Ph.D., Electrical Engineering, Tennessee State University, Nashville, Tennessee, August 2013. Dissertation title: "Development of Integrated Decision Fusion Software System For Aircraft Structural Health Monitoring" M.S., Electrical Engineering, Tennessee State University, Nashville, Tennessee, May 2009. Thesis title: "Development of Software System for Control and Coordination of Tasks among Mobile Robot and Robotic Arm." B.S., Electrical Engineering University of El Mina Cairo, Egypt, May 2001. 


\section{Design and development of Robust Portable Trainers used in PLC and Pneumatic Laboratories}

\section{Introduction}

The lab activities for two undergraduate courses in fluid power and Programmable Logic Controller (PLC) programming share similar activities as far as basic programming for PLCs and actuating pneumatic cylinders and motors. The fluid power course includes discussions and lab activities on pneumatics. Currently, students use 4 trainers that are bound to be used in lab due to their sizes. With no sitting space, it is desirable to use portable desktop trainers which can be used in any classroom. The same issue exists with regards to the PLC course. Previously, the authors had proposed two separate portable desktop units for these lab activities with their corresponding lab activities and they also mentioned their plan to incorporate instrumentation in these lab activities $([1,2,3])$. Currently, there are 21 PLC trainers and a prototype is already being built for the fluid power lab. Further discussion and consideration resulted in identifying some lab activities that can be shared if there were one set of trainers that cater to the need of both courses.

This paper discusses the design and development of an integrated trainer based on the existing trainers. The discussion includes design steps, and material and component selection and specification. A series of lab activities will be proposed which will be used in teaching the lab section of the two undergraduate courses in Mechanical Engineering Technology and Mechatronics Engineering Technology. The ultimate goal of this project, which will be a secondary study, is to seek students input on the use of these trainers in teaching the lab activities.

About the courses

The Department of Engineering Technology offers three undergraduate degrees including Electrical and Computer Engineering Technology (ECET), Mechanical Engineering Technology (MET), and Mechatronics Engineering Technology (MCET). The authors teach in MET and MCET programs for the past 5 years with major focus on fluid power and PLC courses. Their experience indicated that these courses, in particular, fluid power needs specific lectures and related lab activities on automation and PLC programming so that the students will learn about these topics. This is mainly due to the fact that the local industry and both programs' industry advisors suggested that graduates with such skills are in demand, particularly, in pneumatic systems.

At the moment, both of these courses have trainers that are being used in the lab activities. However, these cannot be used interchangeably due to the size of the pneumatic trainers and the design goals (e.g., the trainers were originally designed to serve one course only). Figure 1 shows the current trainer used in each course. As seen in this figure, the current trainers are fairly spacious so that the current lab room can accommodates only four of them. The portable trainers would resolve the space issue in the sense that more trainers can be used in the lab. In addition, one can take the portable trainers to regular classrooms, provided that the classroom has 
compressed air lines. This can be a drawback since not all the classroom are equipped with air drops. However, the instructor can take a portable air compressor with him/her since the proposed trainers do not require high pressure to operate (at most $15 \mathrm{psi}$ ).

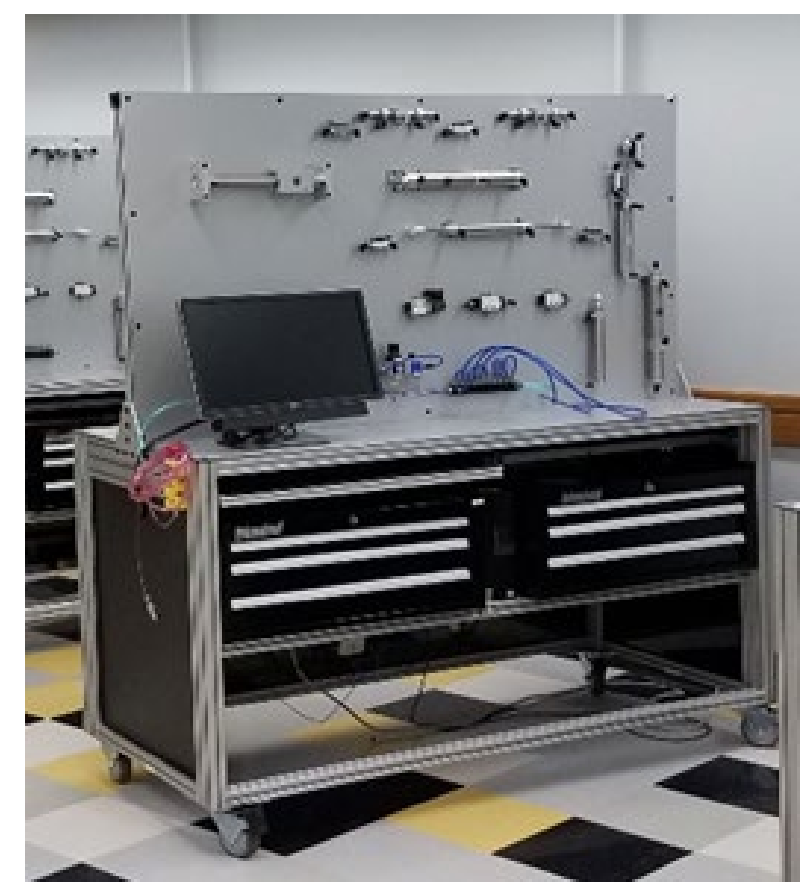

Figure 1. The pneumatic trainers currently used in fluid power course.

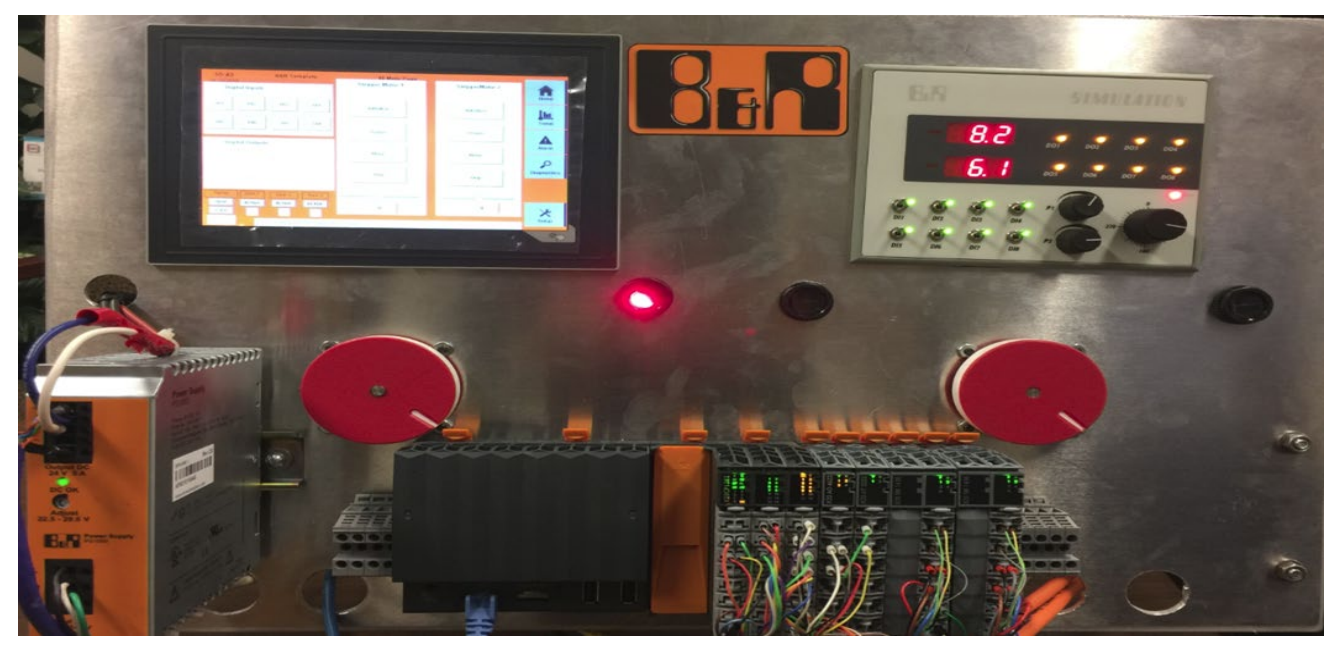

Figure 2. The PLC trainers used in PLC course [5]. 
Design and development details

The authors supervised two senior students to develop and design a prototype of a portable trainer for their project which they delivered and presented last spring. The initial goal was to build several portable trainers so that they could be used in fluid power course during lecture time. This course caters to roughly 24 to 28 students each semester and it would require at least 14 trainers so that groups of two students can work on each trainer. Figure 3 shows the prototype designed and built by the two senior students.

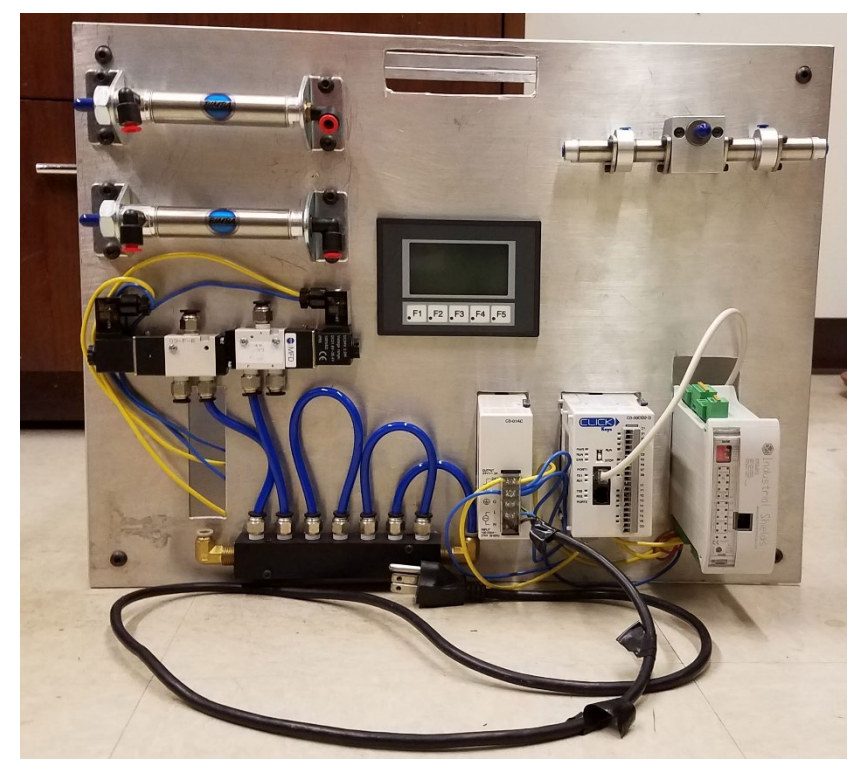

Figure 3. The prototype of the portable trainer.

As further discussed in [3], Table 1 includes the original components intended to build the prototype. However, the design was modified further and so were the components used. Bimba manufacturing was the sole provider of the necessary pneumatic components [4].

Table 3. List of various components needed to build one trainer [3].

\begin{tabular}{|c|c|}
\hline Component & Quantity \\
\hline Double-acting Pneumatic Cylinders & 2 \\
\hline Air Compressor & 1 \\
\hline Power Supply (PS) & 1 \\
\hline Terminal Block (TB) & 4 \\
\hline Limit Switches (LS) & 2 \\
\hline PLC & 1 \\
\hline Solenoid valve & 2 \\
\hline Terminal blocks & 4 \\
\hline Din rail & 1 \\
\hline Mis. (Wires, Input Output ports, etc.) & varies \\
\hline
\end{tabular}


Proposed lab activities

Three lab activities were developed by two senior students under the supervision of the authors. The lab activities have two parts: one for Arduino, an open-source platform to control microprocessors [6], and one for PLC. The usage of microcontrollers will help the MCET coauthor to use the trainers in his course, in particular. The lab activities, with their corresponding diagrams (Figures 4, 5, and 6), include the following activities in order:

- $\quad \underline{L a b ~ 1: ~ U s i n g ~ a ~ c o u n t e r ~ t o ~ a c t u a t e ~ a ~ d o u b l e-a c t i n g ~ c y l i n d e r: ~ t h e ~ o b j e c t i v e ~ o f ~ t h i s ~ l a b ~ i s ~ f o r ~}$ students to extend and retract the cylinder three times.
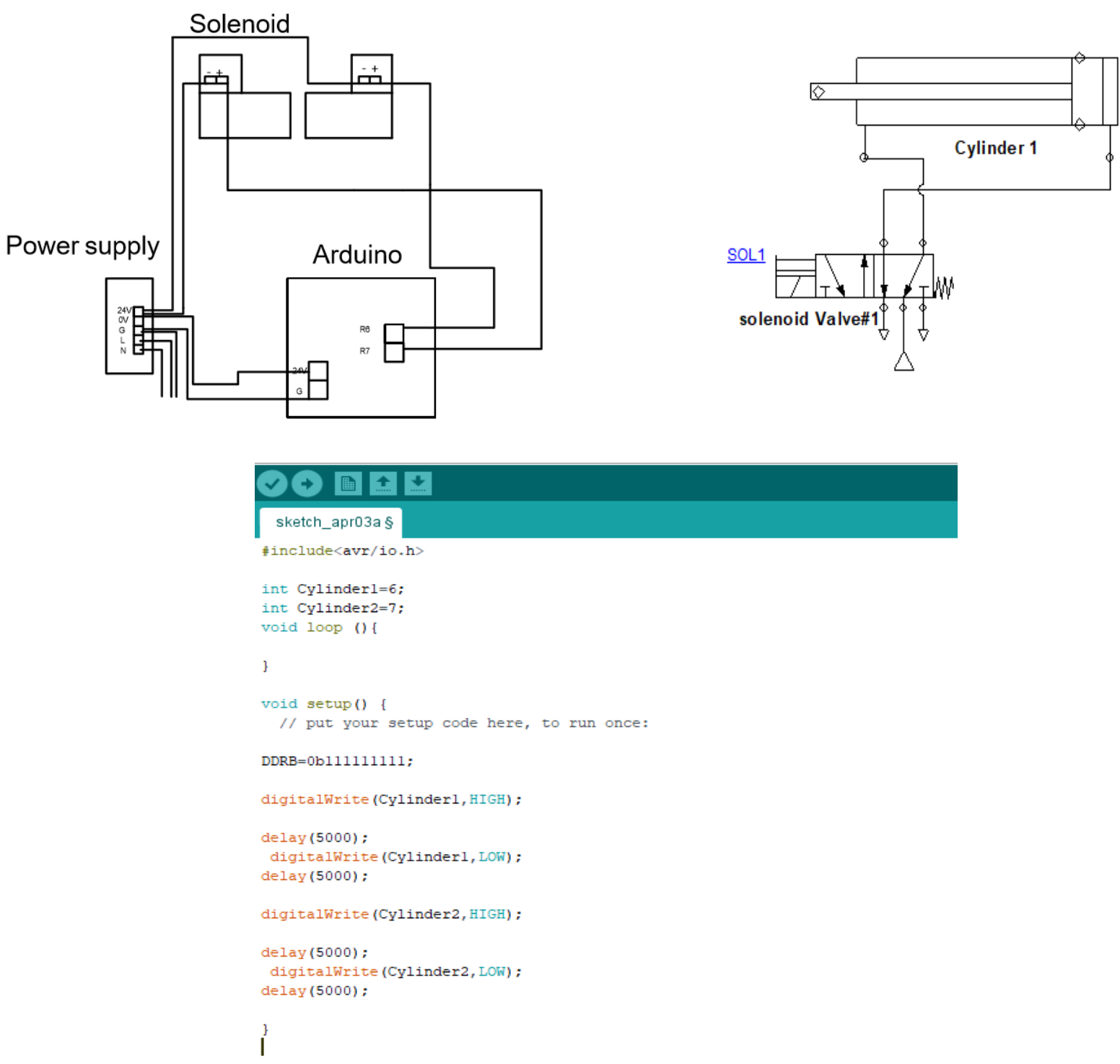

Figure 4. The diagrams for the first lab activities (top left: the electrical circuit, top right: the pneumatic circuit, bottom: Arduino's codes). 
- Lab 2: Using a timer and HMI to actuate two double-acting cylinders: students are to develop a ladder logic so that the cylinders extend with a 5-second delay between each stroke.
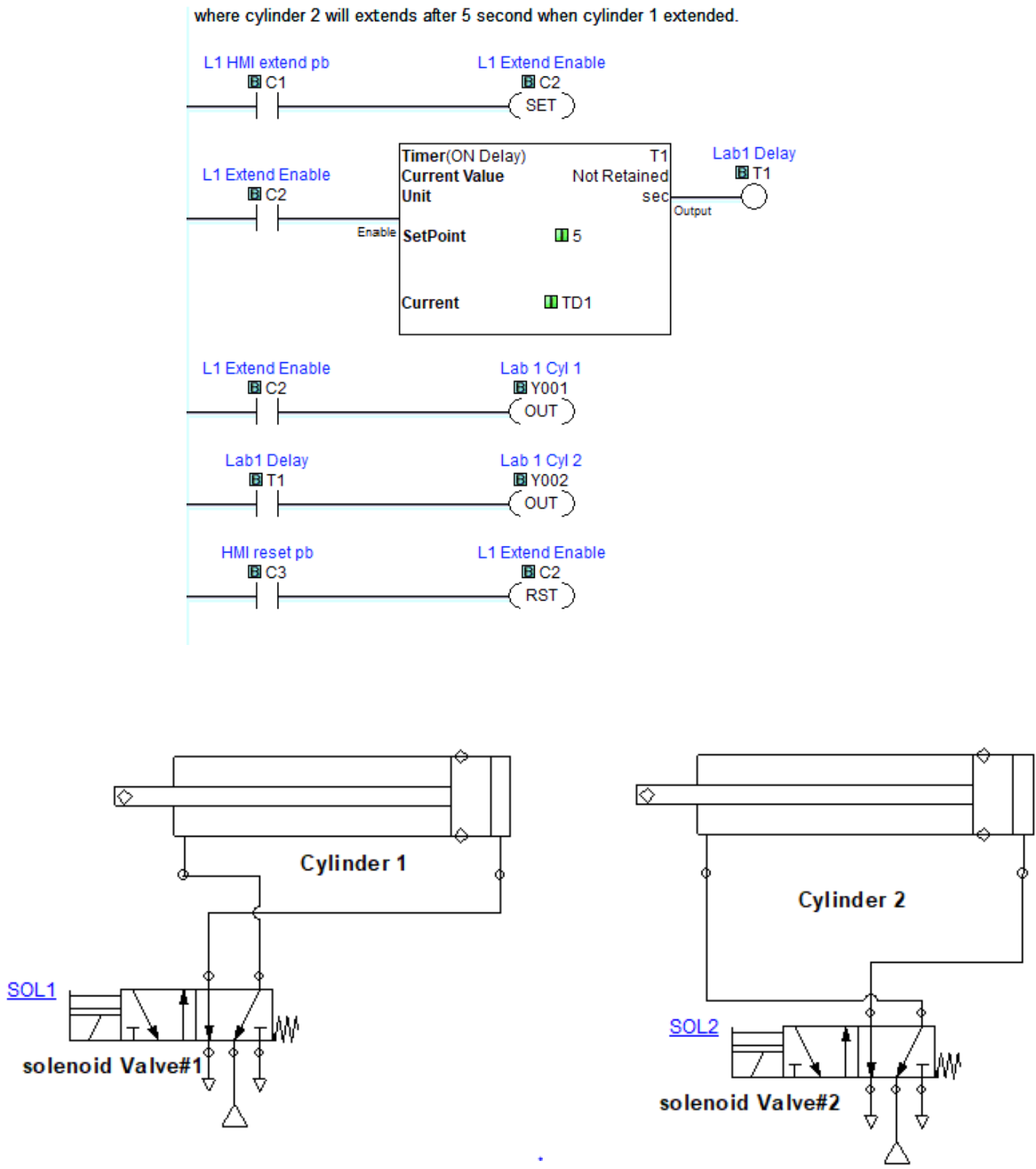

Figure 5. The diagrams for the second lab activities (top: the ladder logic, bottom: pneumatic circuit). 
- Lab 3: Using a timer to actuate a rotary actuator: in this lab, the students are to run the rotary actuator for 5 second using a ladder logic.
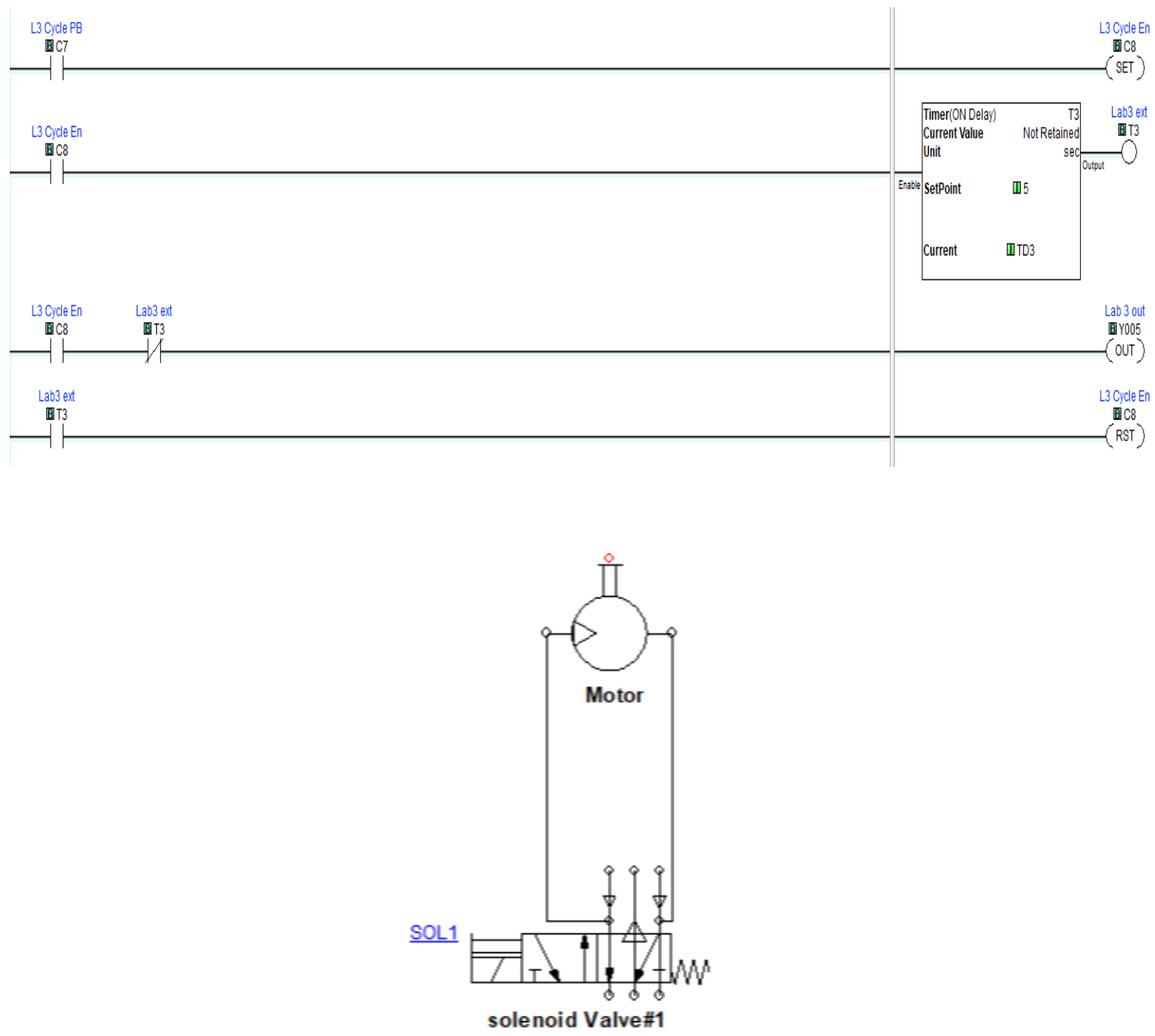

Figure 6. The diagrams for the third lab activities (top: the ladder logic, bottom: pneumatic circuit).

These are new lab activities that have not been used before. A similar design had been developed ([3]) as mentioned before but further discussion resulted in designing these new trainers that will cater to both MCET and MET program.

\section{Conclusion}

The rationale and the steps taken to complete the design and construction of a portable integrated PLC and pneumatic trainer were presented. Also, the proposed lab activities were discussed. The authors are planning to make 13 more such trainers to serve both PLC and fluid power courses. In addition, they will survey the students who will be using these trainers in both courses to learn about the students' evaluation of both the trainers, as well as the lab activities. 


\section{Acknowledgement}

The authors would like to express their gratitude to Mohammad Albannay and Ahmed Alturiki, the senior MCET students who completed the design and construction of the prototype trainer, as well as the lab activities. In addition, the authors are thankful to the Rick Rickerson, the facility supervisor of the College, as well as to Bimba manufacturing for providing the necessary pneumatic components.

\section{Reference}

[1] A. Alavizadeh and M. Mikhail, "Developing PLC-based pneumatic lab activities for an undergraduate course on fluid power," in Proceedings of the American Society for Engineering Education Annual Conference \& Exposition, 2018, Salt Lake City, UT, USA, June 24-27.

[2] A. Alavizadeh and M. Mikhail, "Integrating measurement instruments in pneumatic lab activities," in Proceedings of the American Society for Engineering Education Annual Conference \& Exposition, 2017, Columbus, OH, USA, June 25-28.

[3] A. Alavizadeh and M. Mikhail, "Design and development of portable pneumatic trainers to teach basic PLC wiring and programming," in Proceedings of the American Society for Engineering Education Annual Conference \& Exposition, 2019, Orlando, FL, USA, June 25-28.

[4]. Bimba Manufacturing, Inc. [Online]. Available: https://www.bimba.com/Products-and$\mathrm{Cad} /$ Actuators/Inch/Round-Line/Non-Repairable/Original-Line-Cylinder [Accessed February 1, 2019].

[5]. M. Mikhail, A. Alavizadeh, "Enhancing a Programmable Logic Controller Course," in Proceedings of the American Society for Engineering Education Annual Conference \& Exposition, 2017, Columbus, OH, USA, June 25-28.

[6] Arduino (2020, Jan.). What is Arduino? [Online]. Available:

https://www.arduino.cc/en/Guide/Introduction 